DOI: https://doi.org/10.47405/mjssh.v6i12.1206

\begin{tabular}{|c|c|}
\hline - & Malaysian Journal of Social Sciences and Humanities (MJSSH) \\
\hline Malaysian Journal of & Volume 6, Issue 12, December 2021 \\
\hline (MJ. SSH) & e-ISSN : 2504-8562 \\
\hline & $\begin{array}{l}\text { Journal home page: } \\
\text { www.msocialsciences.com }\end{array}$ \\
\hline
\end{tabular}

\title{
Cabaran dan Kelangsungan Pengusaha Makanan Kecil dalam Pandemik Covid-19
}

\author{
Rima Abdul Rahman ${ }^{1}$, Harifah Mohd Noor ${ }^{1}$, Adilah Md Ramli ${ }^{2}$ \\ 1Fakulti Sains Sosial dan Kemanusiaan, Universiti Malaysia Sabah (UMS), Malaysia \\ 2Fakulti Sains Makanan dan Pemakanan, Universiti Malaysia Sabah (UMS), Malaysia \\ Correspondence: Rima Abdul Rahman (rimar7299@gmail.com)
}

\begin{abstract}
Abstrak
Perusahaan Kecil dan Sederhana (PKS) telah banyak menyumbang dalam memajukan ekonomi negara. Kewujudan perusahaan makanan kecil ini telah banyak membantu dalam meningkatkan pendapatan negara serta turut memberikan banyak peluang pekerjaan kepada masyarakat. Namun, kewujudan pandemik Covid-19, hampir melumpuhkan kelangsungan pengusaha makanan kecil ini. Tujuan kajian adalah untuk mengenal pasti cabaran yang dihadapi oleh pengusaha makanan kecil dan meneliti kelangsungan mereka untuk bertahan dalam era pandemik. Satu set borang kaji selidik diedarkan kepada 120 pengusaha kecil makanan yang berdasarkan kaedah persampelan bertujuan di daerah Kota Kinabalu, Sabah. Analisis data menggunakan kaedah deskriptif dan inferensi menerusi frekuensi, skor min purata dan khi kuasa dua. Penemuan menunjukkan terdapat perkaitan yang signifikan di antara tempoh berniaga dalam perusahaan makanan kecil dengan tahap terkesan kewangan yang mana nilai Khi Kuasa Dua=18.699 dan Signifikan= 0.028. Seterusnya, hasil dapatan menunjukkan cabaran yang dihadapi oleh pengusaha makanan PKS semasa pandemik ini yang menunjukkan sangat terkesan bagi item 'keuntungan semakin berkurang' dengan nilai purata $\min =4.70$ diikuti dengan cabaran bagi item 'terpaksa menjual harta' dengan nilai purata $\min =3.13$. Walau bagaimanapun, pengusaha makanan kecil menyediakan beberapa alternatif untuk kelangsungan perniagaan mereka semasa krisis pandemik ini dengan 'jualan sasaran pembeli tempatan' (purata $\min =4.90)$ merupakan usaha mereka untuk bertahan dalam perniagaan pada masa ini diikuti dengan 'pekerja dalam kalangan keluarga' (purata min=4.40). Melalui kajian ini, cabaran dan kelangsungan untuk pengusaha makanan kecil dapat dikenal pasti dalam era pandemik ini sekaligus dapat membantu pihak berkuasa mengetahui apakah bantuan yang sesuai bagi pengusaha ini berdasarkan kepada cabaran yang mereka hadapi.
\end{abstract}

Kata kunci: cabaran, kelangsungan, pengusaha kecil, pandemik

\section{Challenges and Sustainability of Small Food Entrepreneures in The Covid-19 Pandemic}

\begin{abstract}
Small and medium-sized enterprises (SMEs) have made significant contributions to developing the country's economy. This small food enterprise has significantly increased the country's income while also providing numerous job opportunities in the community. The presence of the Covid-19 pandemic, on the other hand, almost paralyzed the survival of these small food entrepreneurs. The study's goal was to identify the challenges that small food entrepreneurs face and to investigate their ability to survive in a pandemic era. Based on the sampling method, a set of survey forms was distributed to 120 small food entrepreneurs in the district of Kota Kinabalu, Sabah. The frequency, mean score, and chi-
\end{abstract}


square test methods were used to analyze the data and descriptive and inferential methods. The findings show a significant relationship between the period of business in small food enterprises and the level of financial impact, with Chi-Square $=18.699$ and Significance $=0.028$. Furthermore, the findings show the challenges food SMEs face during this pandemic, with a total mean of 4.70 for the item' declining profits' and a mean value of 3.13 for the challenges for the item 'forced to sell assets. However, small food entrepreneurs provided several alternatives for business survival during this pandemic crisis, with 'local buyer target sales' (mean $=4.90$ ) being their existing efforts to stay in business, followed by 'family workers' (average min $=4.40$ ). This research will assess the challenges and sustainability for small food entrepreneurs in this pandemic era and assist authorities in establishing what assistance is appropriate for these entrepreneurs based on the challenges they face.

Keywords: challenges, sustainability, small enterprises, pandemic

\section{Pengenalan}

Perusahaan makanan telah lama menjadi tumpuan dalam setiap negara. Aspek perusahaan makanan turut menjadi salah satu penyumbang terbesar dalam ekonomi negara. Sektor Perusahaan Kecil dan Sederhana (PKS) yang merupakan salah satu sumber kenaikan ekonomi negara ini telah banyak mendapat perhatian dan dibincangkan dalam mesyuarat yang diadakan dengan Menteri Kewangan. PKS ini terdiri daripada tiga jenis perusahaan, pertama perusahaan mikro iaitu kumpulan yang paling besar dalam kegiatan ekonomi negara. Kedua, perusahaan kecil dan ketiga perusahaan sederhana (SME.Corp Malaysia, 2020). Dalam PKS, ia mempunyai pakej Program Subsidi Upah (PSU) yang bertujuan untuk mengelakkan mereka (pekerja) dibuang kerja semasa pandemik sekali gus dapat membantu pengusaha dalam mengekalkan pekerja mereka.

Perusahaan makanan berskala kecil merupakan perusahaan yang memainkan peranan penting dalam sektor ekonomi negara kerana perusahaan ini yang sentiasa menjadi tarikan kepada pelancong luar dan domestik untuk mengunjungi suatu kawasan. Permintaan yang tinggi terhadap produk makanan telah menunjukkan bahawa ekonomi negara sedang berkembang baik. Menurut Keskin et al. (2010), Perusahaan Kecil adalah dalam kategori perusahaan kecil dan Sederhana (PKS) yang mewakili 98.5 peratus daripada komuniti perniagaan termasuk perusahaan mikro, komuniti luar bandar, kumpulan B40 dan pembekal. Perusahaan Kecil dan Sederhana (PKS) dianggap sangat penting kepada pertumbuhan ekonomi negara kerana ianya memberikan peluang pekerjaan dan sumbangan Keluaran Dalam Negeri Kasar (KDNK) yang terbaik kepada negara (Keskin et al., 2010). Pada 2019, PKS mewujudkan 7.3 juta pekerja yang menyumbang sebanyak 48.4 peratus kepada guna tenaga negara sekaligus mengurangkan kadar pengangguran di negara kita (SME.Corp Malaysia, 2020).

Sektor PKS bagaimanapun menghadapi kesukaran dalam meneruskan pekerjaan mereka disebabkan kewujudan isu Covid-19. Cabaran yang paling ketara bagi pihak perusahaan adalah dalam mencari keuntungan. Jika dahulu, perusahaan makanan adalah sektor yang paling mudah untuk mendapatkan pelanggan dan keuntungan namun, keadaan pandemik pada masa ini telah mengurangkan aliran tunai (Wong, 2020). Dalam pada itu, masih banyak perusahaan makanan yang muncul dan bangun dalam pandemik ini. Pelbagai strategi dibina dan digunakan untuk memastikan perniagaan mereka tidak berhenti begitu sahaja. Situasi pandemik Covid-19 pada masa ini telah diklasifikasikan sebagai endemik di mana masyarakat diminta untuk cuba mengadaptasikan diri dengan kewujudan penyakit ini (Fauzi, 2020). Menteri Kesihatan, Khairy Jamaluddin mengatakan bahawa Malaysia harus menerima hakikat bahawa pengakhiran bagi Covid-19 ini adalah peringkat endemik.

\section{Sorotan Literatur}

\section{Kesan Krisis Pandemik COVI-19}


Krisis pandemik covid-19 telah menyebabkan perniagaan yang diusahakan oleh pengusaha PKS semakin terjejas kerana pandemik ini telah mengancam tujuan perniagaan, memberi tekanan kepada pengurusan dan telah menyebabkan kegagalan dalam perniagaan (Hermann, 1963; Penrose, 2000; Lerbinger, 2012). Menerusi kajian oleh Jose et al., (2020) menyatakan bahawa syarikat kecil merupakan perusahaan yang paling terjejas kerana tahap ketersediaan yang lebih rendah, kekangan sumber, kedudukan pasaran yang agak lemah dan pergantungan yang lebih tinggi hanya kepada pemerintah tempatan. Selain itu, perusahaan PKS biasanya mengalami kerugian kewangan, pengurangan jumlah jualan, ketidakupayaan untuk memenuhi syarat kontrak, masalah aliran tunai dan pengurangan kakitangan dalam perniagaan yang mana hal ini telah memberikan tekanan emosi dan psikologi kepada pengusaha PKS (Leung et al., 2005; Ferris et al., 2007; Doern, 2016).

Menurut Cepel et al. (2020) sebanyak 70 peratus perniagaan-perniagaan PKS menyatakan bahawa jika perintah undang-undang penutupan premis perniagaan berterusan selama tiga bula berturut, para pengusaha tidak akan dapat bertahan untuk meneruskan perniagaan mereka dan ini akan menyebabkan mereka akan menutup perniagaan secara kekal. Sepanyol merupakan salah satu negara yang paling terjejas akibat pandemik yang mana ia telah mempengaruhi cara pengusaha PKS beroperasi semasa pandemik kerana risiko seperti gangguan hubungan majikan dan pekerja terganggu, hutang kepada pembekal tertunggak dan gangguan bekalan bahan mentah telah berlaku dan menyebabkan pengusaha ini semakin terjejas (Didier et al., 2020).

\section{Resilien Pengusaha Berhadapan dengan Impak Pandemik COVID-19}

Secara umum, ketahanan dilihat sebagai kemampuan untuk meneruskan kehidupan, atau untuk terus hidup dengan tujuan kehidupan, setelah kesusahan atau kesulitan. Seseorang dapat membina daya tahan melalui perkembangan seharian yang disebabkan oleh peristiwa yang tidak dijangka dalam hidup mereka. Ketahanan difahami sebagai proses di mana individu, komuniti, atau entiti peringkat makro menyesuaikan diri dengan keadaan kontekstual baru (Schepers et al., 2021).

Menurut Harifah et al. (2020) resilien yang digunakan oleh pengusaha PKS untuk menangani isu pandemik adalah menerusi berjimat cermat dalam perbelanjaan, memasarkan produk secara atas talian dan mendapatkan khidmat nasihat serta bimbingan daripada pakar untuk meluahkan rasa kebimbangan terhadap perniagaan pada era pandemik ini. Pihak kerajaan di Malaysia turut memberikan pakej rangsangan PRIHATIN untuk ketahanan pengusaha PKS semasa pandemik ini. Bantuan PRIHATIN yang berbentuk wang tunai dapat membantu pengusaha PKS untuk memperbaiki perniagaan yang terjejas akibat pandemik (Tinjauan Ekonomi, 2020).

Daya ketahanan keusahawanan dapat dilihat dari pelbagai sudut seperti (i) usahawan berkembang kembali ke model perniagaan lama yang dilaksanakan setelah gelombang kejutan pertama, (ii) usahawan mengamalkan tingkah laku perniagaan lestari baru untuk membentuk struktur ekonomi, (iii) usahawan menerima keperluan yang akan berlaku mengubah dan melakukan perubahan radikal dalam model perniagaan mereka dengan inovatif struktur sosioekonomi (Ignat \& Constantin, 2020).

\section{Model Resilien (Daya Tahan) Perusahaan Kecil dan Sederhana}

Menurut Pal et al. (2014) menjelaskan bahawa daya ketahanan PKS dapat dilihat dalam bentuk model yang mana ia terdapat tiga pemboleh ubah daya ketahanan iaitu aset dan kepintaran, berdaya saing dinamik serta pembelajaran dan budaya.

\section{Aset Kekayaan}

Aset adalah ketahanan sumber yang dianggap sebagai kekuatan utama kepada aspek ketahanan. Perspektif ini menggambarkan bahawa PKS yang kekurangan sumber kekayaan dari aspek bahan mentah, aliran wang tunai yang baik akan menghadapi kesukaran untuk bertahan dalam perniagaan. Oleh itu, aset ketahanan ini merupakan daya tahan yang sangat penting dalam menghadapi krisis yang akan berlaku dalam perniagaan. 
a) Sumber bahan dan ketahanan: Aset material seperti bahan mentah, bahan proses dan barang akhir adalah sebagai inventori yang digunakan secara strategik dalam membantu untuk mengatasi masalah gangguan kekurangan sumber dalam perniagaan.

b) Sumber kewangan dan ketahanan: Mobiliti dan simpanan aset kewangan adalah sumber penting untuk merancang aset dalam perniagaan. Sumber ketahanan ini amat penting untuk mencegah kesan yang bakal dialami ketika krisis melanda dan dapat memberikan akses segera kepada insuran perlindungan yang mencukupi.

c) Sumber sosial dan ketahanan: Freeman (2004) menekankan keberadaan sumber manusia, atau orang yang mempunyai kemahiran yang diperlukan, sebagai penyumbang akritik. kepada prestasi organisasi yang unggul. Kerjasama dan kepercayaan yang meningkat di kalangan pekerja penting untuk membezakan organisasi yang berpotensi untuk membantu dalam meningkatkan dan perkembangan perusahaan.

d) Sumber rangkaian dan ketahanan: Hubungan antara organisasi kolaboratif (IOR) melalui penggabungan dan pengambilalihan, pakatan strategik atau bantuan sumber luar untuk membantu perusahaan yang dijalankan. Struktur organisasi yang dijalin menawarkan kecekapan dan kemampuan menyesuaikan diri dengan mengekalkan hubungan terjamin yang baik antara pengusaha dengan pembekal dan antara pengusaha dengan pengusaha yang lain.

e) Sumber keyakinan dan ketahanan: Membangun struktur sosial yang baik dan hubungan antara peribadi yang mampu membantu seorang pengusaha itu untuk terus maju ke hadapan dalam perniagaan dan sentiasa meningkatkan keyakinan diri sebagai kekuatan diri dalam menyelesaikan cabaran dan tidak takut untuk berhadapan dengan masalah yang akan datang serta ia dapat melindungi organisasi dan situasi dalam perusahaan.

\section{Daya Saing Dinamik}

'Daya saing dinamik' yang berkesan mengakibatkan pengembangan dan penyusunan semula kecekapan dalam perniagaan. Daya saing dinamik adalah penting untuk pengaktifan tindak balas dalam menghadapi krisis.

a) Fleksibiliti dan daya tahan: Perusahaan PKS yang fleksibiliti dapat membantu dalam mengambil keputusan yang pantas, komunikasi dalaman yang cekap dan berkesan. Ciri-ciri tingkah laku yang fleksibel dan mudah disesuaikan terbukti menjadi penyokong utama ketahanan PKS. Kepantasan dalam membuat keputusan dan hubungan antara organisasi muncul menjadi penyokong utama potensi PKS untuk menunjukkan kemampuan daya tahan.

b) Kelebihan dan daya tahan: Aspek ini adalah dengan membina kelebihan sumber untuk menjadikan perusahaan semakin kukuh dan sentiasa dapat berhadapan dengan masalah. Kelebihan sumber seperti mesin teknologi dalam perusahaan ini mampu untuk membantu pengusaha dalam proses perkembangan perniagaan sekaligus meningkatkan daya saing.

c) Kukuh dan daya tahan: Kekukuhan organisasi adalah elemen lain yang berkesan untuk mencapai ketahanan dengan menentang gangguan dan membangun kebolehpercayaan. Organisasi yang mantap mempunyai budaya kesedaran kualiti. Aspek ini berkesan dalam perancangan dan sumber daya ketumpatan ketika menghadapi gangguan. Ini meningkatkan kemampuan organisasi untuk mengembangkan kawalan kualiti dalaman terhadap kebolehubahan dan proses kemajuan perusahaan.

d) Rangkaian dan daya tahan: Membangun jaringan dan integrasi pengetahuan untuk kerjasama dalam menghadapi situasi. Jaringan organisasi dan rangkaian seperti itu bukan sahaja dapat mengurangkan risiko krisis tetapi sekaligus menghasilkan kemahiran interpersonal yang mendalam dan hubungan di peringkat sosial. Peningkatan hubungan antara organisasi memungkinkan pelaksanaan keputusan yang cepat dalam PKS, mengembangkan ketergantungan penawaran dan hubungan yang sama dengan institusi kewangan. 


\section{Pembelajaran dan Budaya}

Dalam suasana organisasi, prestasi daya tahan bergantung pada aspek organisasi yang lebih lembut, berkepemimpinan dan mempunyai visi (Seville et al., 2006). Ketahanan ditingkatkan melalui pengembangan pengetahuan khusus individu dan juga secara kolektif dalam organisasi untuk bertindak balas secara berkesan terhadap situasi yang tidak dikenali atau mencabar.

a) Pengurusan kepimpinan pihak atasan membuat keputusan dan ketahanan: Menggambarkan syarikat kecil mempunyai kelebihan yang berkaitan dari segi pembuatan keputusan pantas, keupayaan untuk belajar cepat dan komunikasi dalaman yang cepat menjadikan mereka berorientasi pembelajaran untuk membolehkan ketahanan. Pengambilan keputusan untuk sebagian besar PKS akan mengikuti peranan pihak atasan yang kuat dan tegas serta disokong oleh pasukan pengurusan atasan yang kuat. Dalam banyak keadaan, kesan krisis ekonomi berskala besar dapat dikurangkan dengan ketara melalui kepemimpinan yang berdaya tahan.

b) Kolektiviti dan membuat pertimbangan: Di peringkat organisasi dikatakan sebagai pengumpulan pengetahuan, keberkesanan kolektif dan kepercayaan bersama, penting untuk mengembangkan dinamika koordinat dan interaktif. Identiti kolektif yang kuat ini membawa kepada pengertian organisasi yang konstruktif. Secara operasi, kemampuan belajar dan kesedaran seperti itu menyelaraskan organisasi dan strategi secara kognitif terhadap kehendak krisis untuk membina daya tahan.

c) Kesejahteraan pekerja dan ketahanan: Peranan kemampuan pekerja dalam mengendalikan tanggungjawab, peningkatan berterusan melalui perkongsian pengetahuan, pembelajaran dan pemikiran yang betul sangat penting bagi organisasi untuk membina daya tahan. Oleh itu, bekerjasama secara berkesan di seluruh syarikat membawa kepada kesejahteraan kognitif melalui penyelarasan nilai-nilai organisasi, budaya korporat, visi bersama dan tanggungjawab (asas ideologi) untuk mempromosikan kemampuan pembelajaran adaptif.

Rajah 1: Model Resilien (Daya Tahan) Perusahaan Kecil dan Sederhana

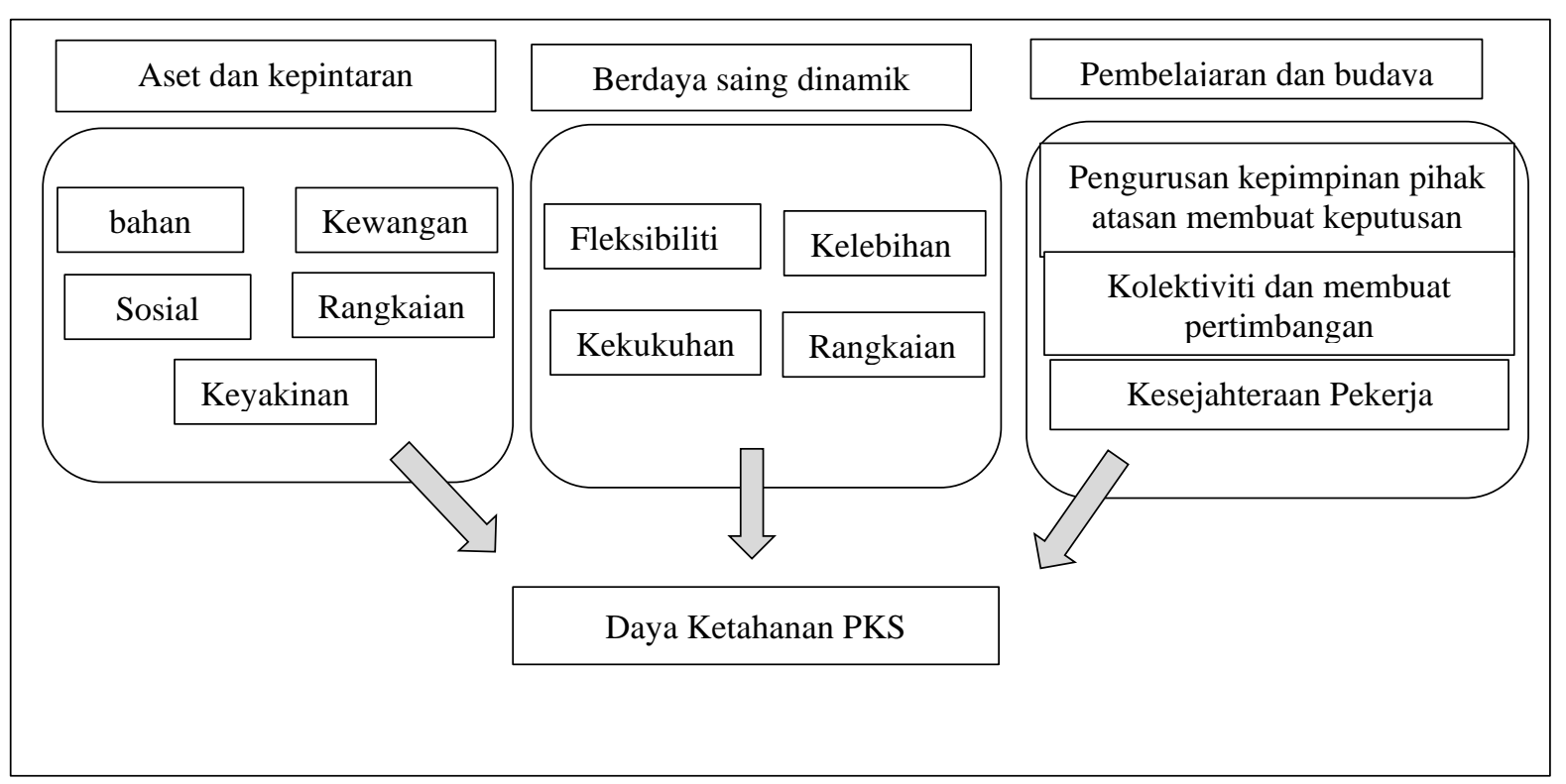

Sumber: Diubahsuai dari Pal et al. (2014) 


\section{Metod Kajian}

Kaedah kajian adalah merupakan strategi, proses dan teknik yang akan digunakan dalam pengumpulan data atau perolehan data kajian yang dijalankan. Kaedah kajian merupakan proses-proses yang akan dilakukan dalam suatu kajian untuk membantu penyelidik agar lebih teliti dan dapat memperoleh maklumat dengan cara yang betul. Kajian yang dijalankan ini merupakan kajian berbentuk deskriptif berbentuk tinjauan. Pendekatan yang digunakan adalah pendekatan kuantitatif dan borang soal selidik merupakan instrumen kepada kajian ini yang mengandungi skala likert 5 tahap iaitu 'Sangat Tidak Setuju', 'Tidak Setuju', 'Sederhana', 'Setuju', 'Sangat Setuju'.

Responden kajian adalah seramai 120 orang responden yang terdiri dalam kalangan pengusaha makanan berskala kecil yang mengusahakan makanan basah dan kering di daerah Kota Kinabalu, Sabah yang mempunyai keluasan $352.2 \mathrm{~km}^{2}$ dengan jumlah penduduknya seramai 527,600 orang. Analisis frekuensi digunakan untuk bahagian demografi responden bagi tujuan melihat kekerapan pada umur, bangsa, pekerjaan sebelum PKS, dan tahap pendidikan. Analisis tabur silang khi kuasa dua digunakan untuk melihat perkaitan tempoh berniaga dalam perusahaan makanan kecil dengan tahap terkesan kewangan. Seterusnya, analisis deskriptif pula digunakan untuk melihat nilai purata min dan sisihan piawai pada Cabaran Pengusaha Makanan Berskala Kecil semasa Pandemik COVID-19. Manakala, min skor digunakan untuk menganalisis kelangsungan pengusaha Makanan Berskala Kecil dalam Pandemik.

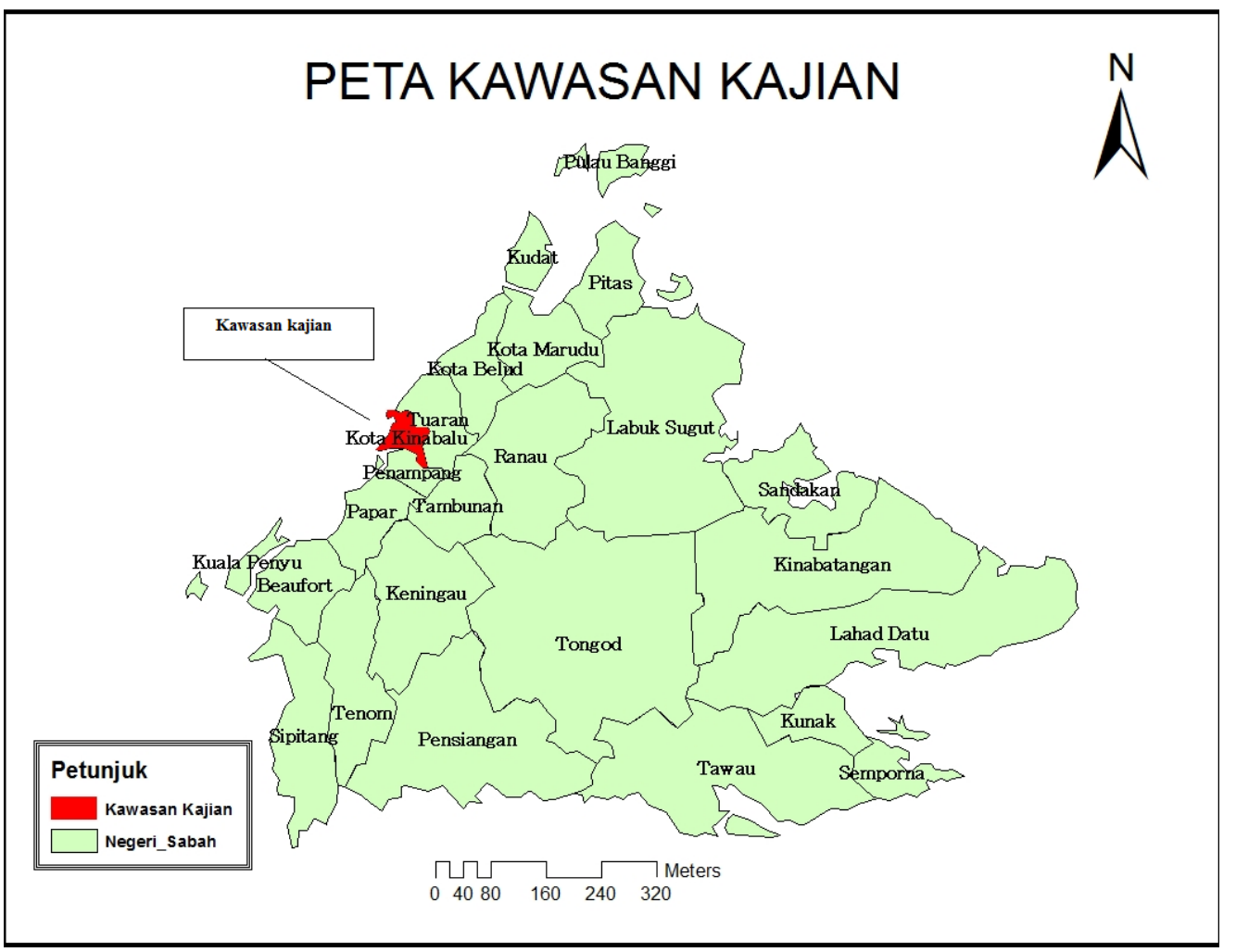

\section{Hasil Kajian}

Hasil kajian menghuraikan tentang demografi responden yang terdiri daripada pengusaha makanan kecil. Selain itu, perkaitan tempoh berniaga dalam perusahaan makanan kecil dengan tahap terkesan kewangan. Selanjutnya, cabaran pengusaha makanan berskala kecil semasa pandemik Covid-19 juga dihuraikan dalam penulisan ini dalam bentuk analisis min skor disertai dengan sisihan piawai. Akhir 
sekali, kelangsungan pengusaha makanan kecil semasa pandemik merupakan hasil kajian yang turut diketengahkan dalam kajian ini.

\section{Demografi Responden}

Jadual 1 menunjukkan peratusan demografi responden dari aspek umur, bangsa, pekerjaan sebelum PKS, dan taraf pendidikan. Majoriti responden berumur 21 hingga 30 tahun ke atas (30 peratus) merupakan responden yang banyak terlibat dalam PKS ini diikuti dengan lingkungan umur 51 tahun ke atas (23.3 peratus). Bangsa Bugis merupakan etnik yang paling tinggi peratusannya mengusahakan produk makanan dengan jumlah 40 peratus diikuti dengan etnik Bajau iaitu 26.7 peratus. Manakala, pengusaha PKS mempunyai latar belakang pekerjaan sebelum PKS yang mana bekerja sendiri merupakan pekerjaan responden sebelum terlibat dalam PKS dengan jumlah 40.8 peratus diikuti dengan pekerjaan swasta (26.7 peratus). Bagi tahap pendidikan pula, responden yang mempunyai latar belakang pendidikan menengah (70.8 peratus) adalah responden yang paling dominan terlibat dalam PKS.

Jadual 1: Demografi Responden

\section{Demografi Responden}

Peratusan $(\%)$

\section{i) Umur}

$<20$ Tahun

21-30 Tahun 30

31-40 Tahun

41-50 Tahun

51 Tahun ke atas

\section{ii) Bangsa}

Bajau

Brunei

Dusun

Iranun

Kadazan

Kedayan

Melayu

iii) Pekerjaan sebelum PKS

$\begin{array}{ll}\text { Kerajaan } & 6.7\end{array}$

$\begin{array}{ll}\text { Swasta } & 26.7\end{array}$

$\begin{array}{ll}\text { Bekerja sendiri } & 40.8\end{array}$

$\begin{array}{ll}\text { Tidak bekerja } & 25.8\end{array}$

\section{iv) Taraf pendidikan}

Rendah

Menengah

Sekolah Tinggi 
DOI: https://doi.org/10.47405/mjssh.v6i12.1206

\section{Perkaitan Tempoh Berniaga dalam Perusahaan Makanan Kecil dengan Tahap Terkesan kewangan}

Hasil dapatan menunjukkan terdapat perkaitan yang signifikan di antara tempoh berniaga dalam perusahaan makanan kecil dengan tahap terkesan kewangan iaitu khi kuasa dua=18.699 dan nilai signifikan $=0.028$. Melalui Jadual 1, dapat dilihat bahawa 100 peratus responden menunjukkan nilai peratusan tertinggi 'sangat terkesan' adalah dalam kalangan pengusaha yang sudah beroperasi dalam tempoh antara 11 hingga 15 tahun. Manakala, 84.8 peratus responden adalah antara responden yang mencatatkan nilai peratusan terendah dalam 'sangat terkesan' bagi tempoh berniaga enam hingga 10 tahun. Bagi tempoh berniaga lima tahun ke bawah pula, ia menunjukkan bahawa hanya 2.3 peratus responden yang 'sangat tidak terkesan'.

Jadual 2: Perkaitan tempoh berniaga dalam perusahaan makanan kecil dengan tahap terkesan kewangan

\begin{tabular}{|c|c|c|c|c|c|}
\hline \multirow[t]{2}{*}{ Tempoh Berniaga } & \multicolumn{4}{|c|}{$\begin{array}{c}\text { Tahap } \\
\text { Terkesan } \\
\text { Kewangan (\%) }\end{array}$} & \multirow[t]{2}{*}{$\begin{array}{c}\text { Jumlah } \\
(\%)\end{array}$} \\
\hline & STK & S & $\mathrm{T}$ & ST & \\
\hline 5 Tahun $\mathrm{K}$ bawah & 2.3 & 9.1 & 0.0 & 88.6 & 100.0 \\
\hline 6-10 Tahun & 0.0 & 15.2 & 0.0 & 84.8 & 100.0 \\
\hline 11-15 Tahun & 0.0 & 0.0 & 0.0 & 100.0 & 100.0 \\
\hline 16 Tahun ke atas & 0.0 & 0.0 & 11.8 & 88.2 & 100.0 \\
\hline
\end{tabular}

Nota: STK-Sangat Tidak Terkesan, S - Sederhana, T- Terkesan, ST- Sangat Terkesan

Khi Kuasa Dua $=18.699$, Signifikan $=0.028$

\section{Cabaran Pengusaha Makanan Berskala Kecil semasa Pandemik Covid-19}

Berdasarkan jadual 2, antara cabaran besar yang dihadapi oleh responden adalah cabaran 'Risiko gulung tikar' dengan peratusan 74.5 peratus 'sangat setuju' dengan keseluruhan min 4.54 serta sisihan piawai pada aras 0.80 . Cabaran kedua yang dapat dilihat adalah bagi cabaran 'keuntungan semakin berkurang' sebanyak 73.6 peratus responden metakannya 'sangat setuju' bersamaan dengan min 4.70 dengan nilai sisihan piawai 0.55 .

Jadual 3: Cabaran Pengusaha Makanan Berskala Kecil Semasa Pandemik COVID-19

\begin{tabular}{llcccccccc}
\hline No. & \multicolumn{1}{c}{ Penyataan } & & \multicolumn{3}{c}{ Peratusan } & & & Min & $\begin{array}{c}\text { Sisihan } \\
\text { Piawai }\end{array}$ \\
\hline & & 1 & 2 & 3 & 4 & 5 & & \\
1 & Keuntungan semakin berkurang & 0.0 & 0.0 & 4.5 & 21.8 & 73.6 & 4.70 & 0.55 \\
2 & Tiada kemasukan aliran tunai & 0.0 & 0.0 & 21.8 & 41.8 & 36.4 & 4.12 & 0.75 \\
3 & Hutang tertunggak & 14.5 & 15.5 & 20.0 & 22.7 & 27.3 & 3.32 & 1.40 \\
4 & $\begin{array}{l}\text { Kesukaran memperoleh bahan } \\
\text { mentah }\end{array}$ & 6.4 & 9.1 & 16.4 & 30.0 & 38.2 & 3.84 & 1.21 \\
5 & Terpaksa menjual harta & 21.8 & 17.3 & 17.3 & 12.7 & 30.9 & 3.13 & 1.55 \\
6 & $\begin{array}{l}\text { Memberhentikan sebahagian } \\
\text { pekerja }\end{array}$ & 23.5 & 10.9 & 11.8 & 0.9 & 52.7 & 3.48 & 1.72 \\
7 & kesukaran meyakinan pelanggan & 3.6 & 3.6 & 24.5 & 6.4 & 61.8 & 4.19 & 1.12 \\
8 & $\begin{array}{l}\text { Tidak dapat beroperasi di premis } \\
\text { asal }\end{array}$ & 0.0 & 3.6 & 20.9 & 8.2 & 67.3 & 4.40 & 0.93 \\
9 & Lokasi jualan menjadi terhad & 0.0 & 3.6 & 14.5 & 23.5 & 58.2 & 4.36 & 0.86 \\
10 & Risiko gulung tikar & 0.0 & 0.0 & 20.0 & 5.5 & 74.5 & 4.54 & 0.80 \\
11 & Terpaksa membuang stok lama & 7.3 & 0.0 & 12.7 & 12.7 & 67.3 & 4.32 & 1.16 \\
\hline
\end{tabular}


Nota: 1 - Sangat Tidak Setuju, 2 - Tidak Setuju, 3 - Sederhana, 4 - Setuju, 5- Sangat Setuju

\section{Kelangsungan Pengusaha Makanan Kecil semasa Pandemik Covid-19}

Jadual 3 menunjukkan kelangsungan bagi pengusaha makanan kecil dalam pandemik. Terdapat 6 usaha yang dilakukan oleh mereka. Antaranya ialah usaha 'jualan sasaran pembeli tempatan', mendapat min paling tinggi iaitu min=4.90 dan berskala Tinggi. Begitu juga dengan 'ambil pekerja dalam kalangan keluarga' dengan min 4.40 dan berskala Tinggi. 'guna E-Dagang untuk pemasaran' dengan min 2.70 bersamaan dengan berskala rendah. E-dagang secara ringkasnya ialah melakukan proses membeli dan menjual dalam talian.

Skala menunjukkan rendah kerana majoriti responden menyatakan secara ringkas bahawa mereka kurang memahami tentang penggunaan cara ini. Lebih-lebih lagi pengusaha yang sudah lama berniaga dan lebih gemar melakukan perniagaan secara fizikal. Bagi "perkhidmatan latihan dan kemahiran percuma', mendapat min 4.20 dan juga berskala tinggi yang mana ia adalah usaha pengusaha dalam kelangsungan perniagaan semasa pandemik ini.

Jadual 4: Kelangsungan pengusaha makanan kecil dalam pandemik

\begin{tabular}{clll}
\hline No. & \multicolumn{1}{c}{$\begin{array}{c}\text { Kelangsungan Pengusaha Makanan Kecil dalam } \\
\text { Pandemik }\end{array}$} & Min & Skala \\
\hline 1 & Guna E-Dagang untuk pemasaran & 2.70 & $\mathrm{R}$ \\
2 & Jualan sasaran pembeli tempatan & 4.90 & $\mathrm{~T}$ \\
3 & Perkhidmatan latihan dan kemahiran percuma & 4.20 & $\mathrm{~T}$ \\
4 & Menghadiri kursus online berkaitan keusahawanan & 3.50 & $\mathrm{~S}$ \\
5 & Penggunaan platform penghantaran makanan secara online & 3.30 & $\mathrm{~S}$ \\
6 & Ambil pekerja kalangan keluarga & 4.40 & $\mathrm{~T}$ \\
\hline
\end{tabular}

\section{Perbincangan Kajian}

Hasil kajian mendapati bahawa terdapat perkaitan yang signifikan antara tempoh berniaga dalam perusahaan makanan kecil dengan tahap terkesan kewangan. Hal ini dibukti oleh SME. Corp Malaysia (2020) yang menyatakan bahawa pelaksanaan Perintah Kawalan Pergerakan (PKP) yang lama akan menjejaskan pengusaha PKS yang mana mereka akan mengalami wang simpanan yang semakin menyusut disebabkan oleh pembayaran sewa, hutang tertunggak kepada pembekal dan permintaan yang semakin menurun daripada pelanggan sejak PKP dilaksanakan. Dapatan kajian ini juga selari dengan kajian Ruochen et al. (2020) bahawa ramai pengusaha yang tidak mampu untuk meneruskan perniagaan terutamanya dalam kalangan perusahaan kecil kerana masalah aliran wang tunai yang semakin serius pada awal pelaksanaan kawalan sosial yang telah menyebabkan segelintir pengusaha mengambil keputusan untuk menutup premis perniagaan untuk selamanya.

Menurut Albonico et al. (2020) dalam kajian 'How the COVID-19 crisis is affecting UK small and medium-size enterprises' turut menyatakan hal sama di mana kesan krisis COVID-19 terhadap PKS dapat dilihat adalah pendapatan yang semakin menurun dalam perniagaan perusahaan PKS. Di mana, kajian beliau menyatakan bahawa kajian survei terhadap pengusaha PKS mendapati bahawa 80 peratus responden yang telah menyatakan keuntungan mereka semakin menurun. Walaupun terdapat pelbagai cabaran dalam perniagaan PKS, namun hasil kajian mendapati bahawa pengusaha mempunyai beberapa inisiatif untuk mempertahankan perniagaan mereka demi kelangsungan perniagaan semasa pandemik ini. Hal ini selari dengan ulasan Berita Harian (2020) yang menyatakan bahawa menteri perdagangan menyarankan penduduk tempatan untuk membeli produk pengusaha PKS. Ini bertujuan untuk memberikan sokongan kepada pengusaha yang hanya bergantung kepada pengguna tempatan 
sebagai alternatif tambahan untuk membantu mereka terus berniaga walaupun dalam krisis pandemik ini.

Selain itu, untuk kelangsungan perniagaan, pengusaha yang melibatkan diri dalam perkhidmatan latihan dan kemahiran daripada pakar adalah salah satu inisiatif pengusaha untuk mendapatkan ilmu pengetahuan berkaitan keusahawanan bagi meningkatkan lagi kreativiti mereka untuk memasarkan produk terutamanya pada era pandemik ini (Laporan Tinjauan, 2020). Hal ini sangat penting kepada pengusaha kerana kemahiran dan pengetahuan yang diperoleh akan digunakan untuk memajukan perniagaan mereka terutamanya dalam era pandemik ini.

\section{Kesimpulan}

Secara kesimpulannya, kajian ini dijalankan untuk mengkaji cabaran dan kelangsungan pengusaha makanan kecil ketika menghadapi pandemik Covid-19. Kajian mengambil tempat di Kota Kinabalu, Sabah. Pengusaha telah menghdapi banyak cabaran semasa menjalankan perniagaan. Pergerakan PKP yang telah dilaksanakan oleh kerajaan sedikit sebanyak telah memberikan kesan negatif kepada pengusaha seperti masalah kemasukan aliran wang dalam perusahaan mereka, penutupan perniagaan secara kekal dan kesukaran memperoleh bahan mentah.

Sebagai cadangan penyelidik, perusahaan makanan berskala kecil yang terjejas mungkin boleh menggunakan iklan Kota Kinabaluan secara responsif. Di mana, penggunaan iklan Kota Kinabaluan responsif ini dapat membantu pengusaha untuk memuat naik gambar produk secara automatik dalam laman web dan media sosial pada bila-bila masa dan ini akan menjimatkan masa pengusaha sekaligus dapat membantu dalam memperkenalkan produk makanan secara kerap kepada pengguna internet yang lain.

\section{Rujukan}

Albonico. M, Mladenov. Z dan Sharma. R. (2020). How the COVID-19 crisis is affecting UK small and medium- size enterprises. Mckinsey and Company. page 1-5

Berita Harian. (2020). Kempen beli barang Malaysia 'talian hayat' PKS. Diakses daripada https://www.bharian.com.my/berita/nasional/2020/09/729022/kempen-beli-barangan-malaysiatalian-hayat-pks pada 18 September 2021

Cepel. M, Gavurova. B, Dvorsky. J dan Belas. J. (2020). The impact of the COVID-19 crisis on the perception of business risk in the SME segment. Journal of International Studies, 248-263. doi:10.14254/2071-8330.2020/13-3/16

Doern, R. (2016). Entrepreneurship and crisis management: The experiences of small businesses during the London 2011 riots. International Small Business Journal, 34(3), 276-302.

Didier, T., Huneeus, F., Larrain, M., \&Schmukler, S. L. (2020). Financing firms in hibernation during the COVID-19 Pandemic. World Bank. https://doi.org/10.1596/33611

Dev, S. M, dan Sengupta. R. (2020). Covid-19: Impact on the Indian Economy. Indira Gandhi Institute of Development Research, Mumbai.

Freeman, S.F. (2004). Beyond Traditional systems thinking: Resilience as a strategy for security and sustainability, $3^{\text {rd }}$ international conference on systems thinking in management session on sustainability. Philadelphia.

Ferris, G. R., Hochwarter, W. A., \& Matherly, T. A. (2007). HRM after 9/11 and Katrina. Current issues in North American HRM, 172-185.

Fauzi Suhaimi. (2020). Fahami Perbezaan Epidemik, Endemik dan Pandemik. Universiti Putra Malaysia.

Harifah Mohd Noor, Jabil Mapjabil, Adilah Md Ramli, Jurry Foo, Ubong Imang dan Rima Abdul Rahman. (2020). Resilien keusahawanan makanan tradisi sebagai produk pelancongan dalam tempoh perintah kawalan pergerakan (PKP) sepanjang pandemik di negeri Sabah. Jurnal of Islamic, Social, Economic and Development (JISID), 5, 50-62 
Hermann, C.F. (1963). Some Consequences of Crisis Which Limit the Viability of Organisations. Administrative Science Quarterly, 12, 61-82.

Ignat. R dan Constantin. M. (2020). Multidimensional facets of entrepreneurial resilience during the COVID-19 crisis through the lens of the Wealthiest Romanian counties. Journal Sustainability. doi: $10.3390 /$ su 122310220

Jose, C. A, Cheng, T. L, Yubo. L dan Wei.H. (2020). Crisis management for Small Business during the COVID-19 outbreak: Survival, resilience and renewal strategies of firms in Macau. Research Square. DOI: https://doi.org/10.21203/rs.3.rs-34541/v1

Keskin. H, Senturk. C, Sungur. O, dan Kiris, H. M. (2010). The Importance of SMEs in Developing Economies. International Symposium on Sustainable Development, June 8-9 2010, Sarajevo

Lerbinger, O. (2012). The Crisis Manager: Facing Disasters, Conflicts, and Failures (2 nd ed.). New York: Routledge.

Leung, G. M., Ho, L. M., Chan, S. K., Ho, S. Y., Bacon-Shone, J., Choy, R. Y., \& Fielding, R. (2005). Longitudinal assessment of community psychobehavioral responses during and after the 2003 outbreak of severe acute respiratory syndrome in Hong Kong. Clinical Infectious Diseases, 40(12), 1713-1720

Laporan Tinjauan PKS. (2020). Dasar, inisiatif dan program pembangunan PKS. Diakses daripada https://smecorp.gov.my/images/pdf/2021/LTPKS/BM/Laporan\%20Utama/2.\%20Tinjauan\%20PK S\%202019_20\%20-\%20Bab\%201.pdf pada 20 September 2021.

Najmi Syahiran Mamat. (2020). PKP: Perusahaan keropok lekor Terengganu jalani 'normal baharu'. Astro Awani. Diakses melalui 20 June 2020, daripada laman web http://www.astroawani.com/berita-malaysia/pkp-perusahaan-keropok-lekor Terengganu-jalaninormal-baharu-238633

Penrose, J.M. (2000). The Role of Perception in Crisis Planning. Public Relations Review, 26(2), 155171.

Pal. R, Torstensson. H, dan Mattila. H. (2014). Antecedents of organizational resilience in economic crises-an empirical study of Swedish textile and clothing SMEs. International Journal Economics, 147, 410-428.

Ruochen Dai, Hao Feng, Junpeng Hu, Quan Jin, Huiwen Li, Ranran Wang, Ruixin Wang, Lihe Xu, and Xiaobo Zhang. (2020). The Impact of COVID-19 on Small and Medium-sized Enterprises: Evidence from Two-wave Phone Surveys in China. Center for Global Development.

Seville. E, Brundson. D, Dantes, A. L, Masurier. J, Wilkinson. S and Vargo. J. (2006) Building organization. Currency Doubleday, New York.

Siti Masayu Rosliah Abdul Rashid dan Fatimah Hassan. (2020). Amalan dan Penglibatan Peniaga Kecil melalui Perniagaan Digital Semasa Pandemik Covid-19 di Malaysia. Geografi, 8(2), 1-20. Doi.org/10.37134/geografi.vol8.2.1.2020.

SME. Corp Malaysia. (2020). COVID-19: Kesan terhadap Perniagaan dan PKS - Perspektif global, rantau \& nasional. Diakses daripada https://smecorp.gov.my/images/pdf/2021/LTPKS/BM/Laporan\%20Utama/6.\%20Tinjauan\%20PK S\%202019_20\%20-\%20Sorotan\%20Khas.pdf pada 22 September 2021.

Schepers. J, Vandekerkhof. P dan Dillen. Y. (2021). The Impact of the COVID-19 crisis on growthoriented SMEs: Building entrepreneurial resilience. Journal Sustainability. https://doi.org/10.3390/su13169296

Tinjauan Ekonomi. (2021). Tinjauan ekonomi. Diakses daripada file:///C:/Users/User/Desktop/tinjauan-ekonomi-2021.pdf pada 24 September 2021.

Wong Hua Siong. (2020). Tinjauan tentang kesan COVID19 dan isu perundangan terhadap perusahaan kecil dan sederhana (PKS) di Malaysia. International Journal of Law Government and Communication 5(21):72-82 DOI:10.35631/IJLGC.521007 